\title{
The Roles of miRNAs in Medulloblastoma: A Systematic Review
}

\author{
Behrouz Mollashahi ${ }^{1}{ }^{1 *}$, Fateme Shaabanpour Aghamaleki ${ }^{1, *}$, Abolfazl Movafagh ${ }^{2}$ \\ ${ }^{1}$ Department of Cellular-Molecular Biology, Faculty of Biological Sciences and Technologies, Shahid Beheshti University, ${ }^{2}$ Department of Medical \\ Genetics, School of Medicine, Shahid Beheshti University of Medical Sciences, Tehran, Iran
}

\begin{abstract}
Medulloblastoma is considered one of the most threatening malignant brain tumors with an extremely high mortality rate in children. In the medulloblastoma, there are several genes and mutations found to work in an unregulated manner that works together to push the cells into a cancerous state. With the discovery of non-coding RNAs such as microRNAs (miRNAs), it has been shown that a different layer of gene regulations may be disrupted which would cause cancer. This fact led scientists to put their focus on the role of miRNAs in cancer. A mature miRNA contains a seed sequence which gives the miRNA to identify and attach to the interest mRNA; this attachment may lead degradation of mRNA or suppress of translation of the mRNA. The expression of miRNAs in medulloblastoma shows that some of these non-coding RNAs are overexpressed (OncomiRs) which help cells to proliferate and keep their stemness features. On the other hand, there are other forms of these miRNAs which normally inhibit cell proliferation and promote cell differentiation (tumor suppressor). These are down-regulated during cancer progression. In this systematic review, we attempted to gather several important studies on miRNAs' role in medulloblastoma tumors and the importance of these non-coding RNAs in the future study of cancer.

(J Cancer Prev 2019;24:79-90)
\end{abstract}

Key Words: microRNAs, Neoplasms, Medulloblastoma, Oncogenes, Tumor suppressor genes

\section{INTRODUCTION}

Brain tumors are classified as either benign, malignant or cancerous tumors based on their degrees of progression. To be more precise, the malignant tumors are comprised of grade III and IV, and the benign tumors are those of I and II. Malignant brain tumors or cancerous tumors are divided into primary and secondary tumors which secondary type is associated with metastasis [1,2]. In contrast to adult brain tumors, this kind of tumors has a primary origin in children. Malignant brain tumors consist of pilocytic astrocytoma, ependymoma and medulloblastoma in children and include Glioblastoma Multiforme (GBM), oligodendroglioma and meningioma in adult based on their origin. Medulloblastoma (World Health Organization IV) is the most common malignant tumor of the central nervous system in children and is estimated to be around 0.5 per 100,000 in children younger than 15 years, it consists of about $20 \%$ of the total brain tumors in children [3,4]. Medulloblastoma belongs to central nervous system primitive neuroectodermal tumor family, and it is originating in towards the back and the bottom of the brain and in the cerebellum or posterior fossa. The medulloblastoma tumors can metastasize to the spinal cord which is accompanied by an unpleasant prognosis [5]. Medulloblastoma is also seen in Gorlin syndrome as well as Turcot syndrome [6-8]. With the recent advances in medical sciences and myriads of treatments such as surgery, radiation, and adjuvant chemotherapy, still the outcome of the treatments used for the patients diagnosed with medulloblastoma is poor, and less than $50 \%$ of medulloblastoma patients achieve complete remission within 5 years [9]. Additionally, survivors after a long

Received February 25, 2019, Revised March 27, 2019, Accepted May 13, 2019

Correspondence to: Abolfazl Movafagh

E-mail: movafagh.a@sbmu.ac.ir, ORCID: Abolfazl Movafagh, https://orcid.org/0000-0001-7402-7677

*These authors contributed equally as the co-first author.

Copyright (C) 2019 Korean Society of Cancer Prevention

(c) This is an Open Access article distributed under the terms of the Creative Commons Attribution Non-Commercial License (http://creativecommons.org/licenses/by-nc/4.0) which permits unrestricted non-commercial use, distribution, and reproduction in any medium, provided the original work is properly cited. 
period of treatment suffer from neurological defects including intellectual and developmental impairments because of multiple therapies that affect children brains during their brain development [10]. Based on the mutations of the genes, there are four distinct molecularly classes of medulloblastoma which can be specified in classes of WNT, SHH, Group 3 and Group 4. The first class consist of $10 \%$ of total medulloblastoma tumors and show abnormal activation of Wingless (WNT) signaling and mutations of CTNNB1 and DDX3X in 50\% to $85 \%$ of cases [11]. The second group of medulloblastoma based on molecular pathologies shows $30 \%$ of deranged Sonic Hedgehog (SHH) signaling. These tumors display classic or nodular/desmoplastic histology, 9q deletion in 50\% of the cases and also positive immunohistochemistry for SFRP112 or GAB1 has been noticed $[12,13]$. The biological attributes of Group 3 and 4 medulloblastomas are unclear yet. Group 3 tumors contain a high percentage of large or anaplastic cells. Also, MYC gene amplification and MYC target gene expression are considered as the main characteristic of this class. Isochromosome $17 \mathrm{q}$ and KCNA1 function as immunohistochemical markers that are seen in group 4 of medulloblastoma [14]. Furthermore, several proteincoding genes mutation and expression modification are seen in medulloblastoma patients that act as medulloblastoma pathogenesis [15]. There are other existing mechanisms that control gene expressions, such as, noncoding RNAs like microRNAs (miRNAs) and lncRNAs, DNA methylation and histone modifications. Any dysregulation in these mechanisms leads to medulloblastoma and its progression [16].

miRNAs are small, endogenous noncoding RNA that is $22 \mathrm{nt}$ in size $[17,18]$. Most of these molecules originate from a primary molecule called pri-miRNA which after several consecutive processes create mature miRNA. RNA. Pol II/III transcribe DNA sequences into primary miRNAs which are further processed into pre-miRNA by DiGeorge Syndrome Critical Region 8 (DGCR8) and a ribonuclease III enzyme, Drosha. When pre-miRNA is generated, it is exported into the cytoplasm by an exportin 5 complex and is then processed by RNase III endonuclease Dicer $[19,20]$. This process results in the formation of mature miRNA. The integration of miRNA into the RNA induced silencing complex (RISC) produces the functional miRNA that can exert its function. In most cases, miRNAs bind to 3' UTR of the target mRNA to induce mRNA degradation and inhibit translation. However, there are some exceptions in the miRNAs that interact with another region including 5' UTR, coding sequence and gene promoter. In some situations, miRNAs can induce translation and control transcription. miRNA-mediated gene silencing occurs via the miRNA induced silencing complex (miRISC) including the guide RNA and Argonaut protein family (AGO) which is the most crucial part of the RISC complex. The specificity function of miRISC depends on the interaction of complementary sequences on target mRNA (miRNA response elements) with miRNA of miRISC. When the miRNA-mRNA interaction is complete, AGO2 endonuclease activity is induced to cleavage target mRNA. Although, this interaction destabilizes the connection between AGO and ' ' end of miRNA promoting its degradation [17,21]. The activity of miRNA molecules depends on several factors, such as miRNA location in the cell, the amount of miRNA and its target, and the affinity of miRNA-mRNA interaction. miRNAs play critical roles in cell proliferation and differentiation, and have major roles in embryogenesis, including brain and spinal cord development and neurogenesis [22]. miRNAs may display their roles in a wide variety of human cancer by dysregulating the expression of various oncogenes and tumor suppressors genes, tumor development, progression, chemosensitivity and cellular senescence $[23,24]$. The broad functions of these non-coding RNAs make them a valuable therapeutic target for cancer treatment. The first studies of miRNA expression in brain tumor were done on pituitary adenomas and glioblastomas (GBM) in 2005. Since that time, more studies have examined miRNAs in adult GBM and anaplastic astrocytoma, oligodendrocytic tumors, and glioma cell lines [25,26]. Additionally, several other types of researches have been published in order to shed light on the miRNAs roles in medulloblastoma in both pediatric and adult populations. This review will focus on existing literature on miRNAs and explain their role in the tumorigenesis of medulloblastoma.

\section{SEARCH STUDY AND CLASSIFICATION OF IMPORTANT STUDY}

We searched PubMed Central for studies published until 15 October 2018 using the search strategy "mir"[All Fields] AND ("medulloblastoma"[MeSH Terms] OR "medulloblastoma"[All Fields]). We obtained 2,292 published studies from the initial search, 685 of which were identified as publications regarding miRNAs in medulloblastoma, to select the more informative studies to elucidate the potential of total miRNAs (circulate miRNA and other miRNA) roles in medulloblastoma. Studies that used a small sample size of $<100$ patients and reported relatively poor performance (defined as using preliminary techniques and not validated) were excluded. Using these criteria, we identified 117 high-quality studies that were eligible for this systematic 
review (Fig. 1).

As shown in Figure 2, the studies were published between 2007 and 2018 and the number of articles fluctuates over the years. Our research indicated that so far, few studies have focused solely on this important subject and we need more and extensive studies in this area of medulloblastoma.

\section{microRNAs ROLE IN CANCERS}

Cancer is a complex and multifactorial disease that a variety of factors, such as genetics and environmental factors are involved in its progression $[27,28]$. Firstly, scientists thought that only genes encoding proteins involved in the progression of tumors and tumorigenesis, but with the development of medical sciences and the whole genome project analysis revealed that some noncoding RNA, such as miRNAs also play a major role in tumorigenesis and cancer development [29,30]. miRNAs play a critical role in post-transcriptional regulation and thus regulation of cellular function hence any malfunction in this regulatory system leads to abnormal expression of miRNAs and a variety of disorders such as cancers [31]. The term "oncomiRs" is used for those miRNAs which play an important role in cancer development [32]. Epigenetic regulation of miRNAs including DNA hypomethylation, increased DNA methylation and disruption of the histone modification patterns in the miRNAs locus, are higher than protein-encoding genes. miRNAs genes may be silenced in some human tumors by aberrant hypermethylation of

MEDLINE searching until 15 October 2018 2,292 papers

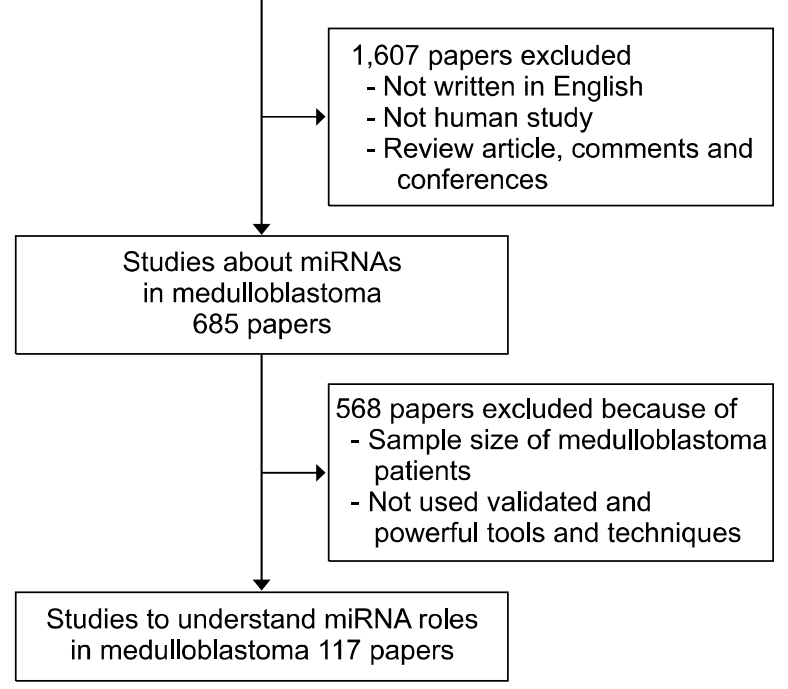

Figure 1. Workflow for this systematic review. miRNA, microRNA.
CpG Island that surrounds or locates close to miRNAs genes and/or by histone modification [33]. miR-127 is located within CpG island and down-regulated in cancer cells which are accompanied by the up-regulation of proto-oncogene BCL6. These results indicate that DNA hypermethylation and histone deacetylation of miRNAs genes affect their expression and function [33-35]. Similarly, decreased expressions of miR-9-1 [36], miR-124a and miR-145-5p [37,38] are contributed to DNA hypermethylation in breast, lung and colon carcinomas. These observations bookmarked the role of epigenetic regulation in miRNAs expression during tumorigenesis. Genomic miRNA copies number and gene locations (amplification, deletion, or translocation) contributed to miRNAs expression modifications in malignant cells. The first observation for miRNAs role in human cancer was derived from a study on chronic lymphocytic leukemia that had common deletions in chromosomal region $13 q 14$ and down-regulation of miR-15-a and miR-16-1 in approximately $69 \%$ of the patients $[39,40]$. Further studies have shown that miR-15 and miR-16 play crucial roles as tumor suppressors and induce apoptosis by repressing Bcl 2 in malignant nondividing B cells and many solid malignant tumors. About 50\% of all miRNAs are located within fragile sites in a genome or in the region that are amplified or deleted in human cancer [41]. A decreased expression of both miR-143 and miR-145 on 5q33 locus caused by deletion within this region causes lung cancer [42]. Also, miRNAs have the potential for being used as a diagnostic and prognostic biomarker and cancer therapy by targeting them. The miR-155 and let-7a expression were seen in lung cancer and can be used as biomarkers for the diagnosis of the disease $[43,44]$. miR-143 can be used as a prognostic biomarker for colorectal cancer in KRAS wild-type patients [45,46]. miRNAs can act as

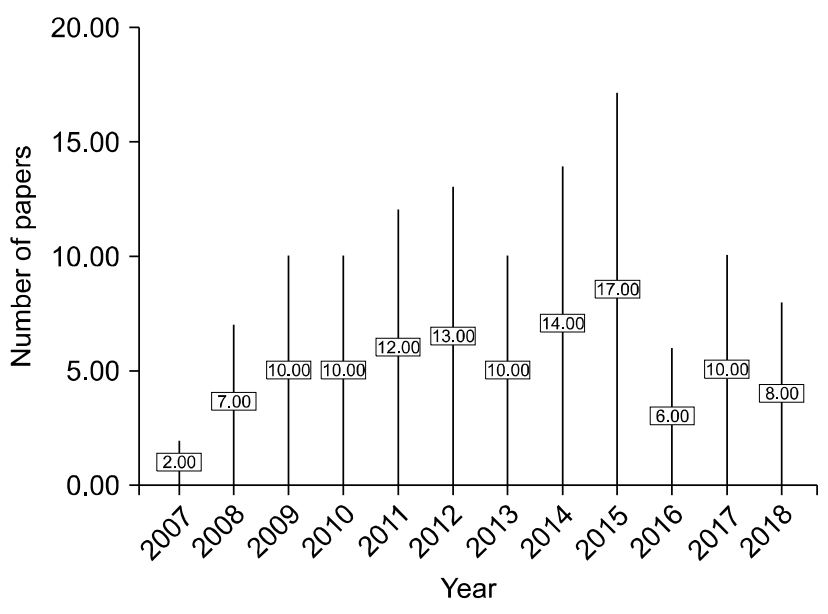

Figure 2. The distribution and number of published studies have been shown in each year. 
oncogenes or as tumor suppressors by influencing tumor suppressors and oncogenes expressions. Oncogenic miRNAs are up-regulated and tumor suppressor miRNAs are down-regulated in cancers. Olive et al. [47] was identified that c-Myc up-regulated in many tumors and activate transcription of the oncogenic miR-17-92 cluster that associated with several cancers like lung, leukemia and brain cancer, through binding to E-box elements in the miR-17-19 promoter.

\section{microRNAs IN MEDULLOBLASTOMA}

Currently, about 1,917 human mature miRNAs are discovered and registered into miRBase release 22 databases (http://www. mirbase.org/). A various number of expression profiles of medulloblastoma have been released that indicate miRNAs roles and molecular significances in cancer development and progression. There are approximately 8,000 microarrays and
RNA-seq data in Geo datasets for medulloblastoma. One of the first miRNAs expression profiling for medulloblastoma was achieved by Ferretti et al. [48] on 31 primary medulloblastomas that led to the exploration of 250 miRNAs and 31 significant miRNAs with changes in their expression pattern. They identified several miRNAs that were associated with tumorigenesis and progression of medulloblastoma. Different biological pathways are affected by miRNAs in the formation and progression of medulloblastoma tumors (Fig. 3). Their expression modifications are associated with medulloblastoma. Mostly, the miRNAs in medulloblastoma play a different number of roles in WNT, SHH and MAPK pathways, as transcriptional repression. They have various functions in tumor cells, such as acting as tumor suppressors like miR-125b, miR-324-5p, and miR-326 that suppress the SHH pathway. On the other hand, some miRNAs act as oncomiR such as cluster miR-17/92 family members that play a role in the SHH pathway that increases cells proliferation when

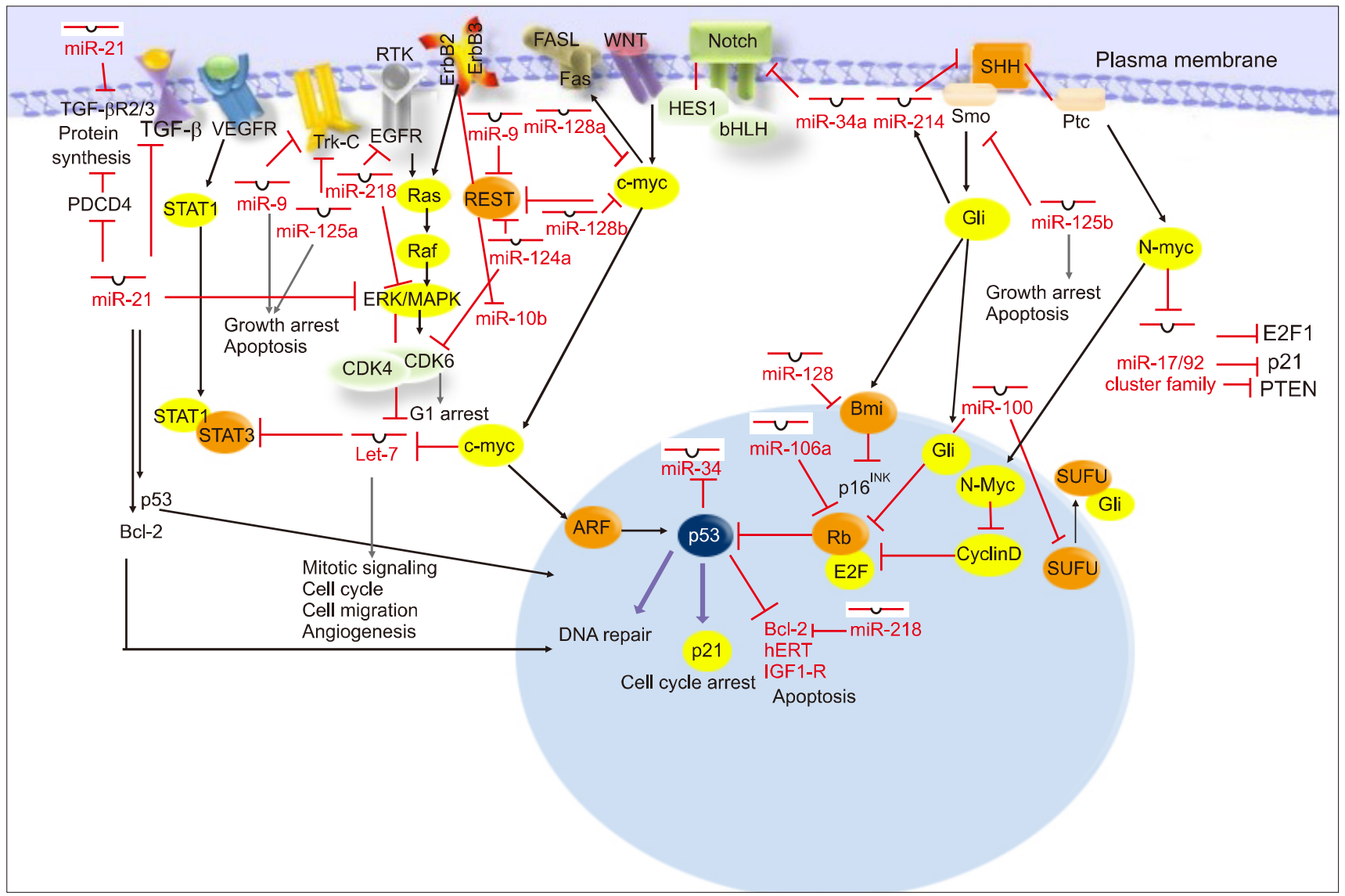

Figure 3. The relationship among aberrantly expressed/functioning microRNAs (miRNAs) and major cancer pathways associated with medulloblastoma. TGF- $\beta$, transforming growth factor beta; VEGFR, vascular endothelial growth factor receptors; EGFR, epidermal growth factor receptor; RTK, receptor tyrosine kinases; FASL, fas ligand; SHH, sonic hedgehog; STAT, signal transducer and activator of transcription; PDCD4, programmed cell death 4: CDK, cyclin-dependent kinase; ARF, alternative reading frame; PTEN, phosphatase and tensin homolog; IGF1-R, insulin-like growth factor receptor; ERK, extracellular-signal-regulated kinase; MAPK, mitogen activated protein kinase. 
Table 1. The most frequent dysregulated miRNAs involved in the pathogenesis of medulloblastoma

\begin{tabular}{|c|c|c|c|c|}
\hline miRNA & Observation & $\begin{array}{l}\text { Functional } \\
\text { target }\end{array}$ & $\begin{array}{l}\text { Representative } \\
\text { target }^{\mathrm{a}}\end{array}$ & $\begin{array}{c}\text { Reference } \\
\text { No. }\end{array}$ \\
\hline miR-17/92 & Up-regulated & $\begin{array}{l}\text { SHH pathway } \\
\text { MYCN/MYC } \\
\text { Gli1 }\end{array}$ & $\begin{array}{l}\text { ZNFX1 } \\
C C L 1 \\
\text { GPR137B } \\
\text { NABP1 }\end{array}$ & [47] \\
\hline Let-7g & Up-regulated & $\begin{array}{l}\text { RAS } \\
\text { STAT3 }\end{array}$ & $\begin{array}{l}C D K 6 \\
C D C 25 A \\
\text { KRAS } \\
\text { MYC }\end{array}$ & [52] \\
\hline miR-199-5p & Up-regulated & $\begin{array}{l}\text { HES1 } \\
\text { Notch pathway } \\
\text { ErbB2 }\end{array}$ & $\begin{array}{l}H E S 1 \\
E T S 2 \\
M E C P 2\end{array}$ & [50] \\
\hline miR-214 & Up-regulated & $\begin{array}{l}\text { SHH pathway } \\
\text { Gli1 }\end{array}$ & $\begin{array}{l}\text { EZH2 } \\
P T E N \\
D A P K 1\end{array}$ & [53] \\
\hline miR-9 & $\begin{array}{l}\text { Down- } \\
\text { regulated }\end{array}$ & $\begin{array}{l}\text { REST/NRSF } \\
\text { t-Trk-C }\end{array}$ & $\begin{array}{l}\text { TP53INP1 } \\
M M P 13 \\
R E S T\end{array}$ & \\
\hline miR-125a & $\begin{array}{l}\text { Down- } \\
\text { regulated }\end{array}$ & $\begin{array}{l}\text { REST/NRSF } \\
\text { t-Trk-C }\end{array}$ & $\begin{array}{l}\text { CDKN1A } \\
\text { LIN28A } \\
\text { TP53 } \\
\text { LIF }\end{array}$ & [54] \\
\hline miR-124a & $\begin{array}{l}\text { Down- } \\
\text { regulated }\end{array}$ & CDK6 & $\begin{array}{l}\text { SOX9 } \\
B D N F \\
\text { EFNB1 }\end{array}$ & [55] \\
\hline $\mathrm{miR}-125 \mathrm{~b}$ & $\begin{array}{l}\text { Down- } \\
\text { regulated }\end{array}$ & $\begin{array}{l}\text { Smo } \\
\text { Gli1 }\end{array}$ & $\begin{array}{l}\text { BMPR1B } \\
\text { EIF4EBP1 } \\
\text { HMGA2 }\end{array}$ & [56] \\
\hline miR-324-5p & $\begin{array}{l}\text { Down- } \\
\text { regulated }\end{array}$ & $\begin{array}{l}\text { Smo } \\
\text { Gli1 }\end{array}$ & $\begin{array}{l}\text { SMO } \\
\text { GLI1 } \\
W N T 9 B\end{array}$ & [57] \\
\hline miR-326 & $\begin{array}{l}\text { Down- } \\
\text { regulated }\end{array}$ & $\begin{array}{l}\text { Smo } \\
\text { Gli1 }\end{array}$ & $\begin{array}{l}\text { GLI1 } \\
\text { SMO } \\
\text { NOTCH1 } \\
\text { NOTCH2 }\end{array}$ & [49] \\
\hline miR-218 & $\begin{array}{l}\text { Down- } \\
\text { regulated }\end{array}$ & $\begin{array}{l}\text { EGFR } \\
\text { Bcl-2 }\end{array}$ & $\begin{array}{l}M B N L 2 \\
E F N A 1 \\
N U P 93 \\
E B P\end{array}$ & [51] \\
\hline
\end{tabular}

The important microRNAs (miRNAs) with their pathways are considered in this table. It also provides the targeted genes of miRNAs. amiRNAs target according to miRTarBase.

overexpressed [48]. To identify validated miRNAs, we listed the ten most frequently documented miRNAs in the identified studies as shown in Table 1 [47,49-57]. The reported and three representative target genes, which were identified according to miRTarBase (http://mirtarbase.mbc.nctu.edu.tw/), are also listed. To show the function and importance of these miRNAs in medulloblastoma, several well-designed studies are presented as examples.

\section{1. miRNA 17 to 92 serves as OncomiR in medulloblastoma}

miRNAs belong to different classes of genes known as non-coding RNAs which do not encode any proteins, these RNAs consist of 22-24 nt and mostly they act as a post-transcriptional regulation by degrading or hindering translation of the target mRNAs. The seed sequence is the functional part of a miRNAs (2-7 $n t)$ in which seed sequence identifies the mRNA of the interest [58]. Less than $50 \%$ of miRNAs are located within the gene clusters, that is, genes that share similar function and are often located within a few thousand base pairs of each other [59]. These are mostly conserved in their sequences especially the seed sequence [60].

The miR-17 to 92 belong to the family of three clusters genes which is located on different chromosomes [61]. The miR-17to 92 cluster also known as Oncomir-1, are identified as potential oncogenes [62]. It is shown that miR17 to 92 has the polycistronic gene and six different miRNAs can be processed from the single precursor RNA of the miR-17 to 92 (miR-17, miR-18a, miR-19a, miR-20a, miR-19b-1, and miR-92-1). These are classified into four groups based on their seed sequence [63]. The miR-17 to 92 role in the pathogenesis of human cancer has been shown in Burkitt's lymphoma, diffuse large B-cell lymphoma, mantle cell lymphoma, follicular lymphoma, and several other solid tumors such as small cell lung cancer in which frequent amplification and overexpression occur in its locus on $13 q 31[47,58,62,64]$. The other mechanism in which miR-17 to 92 cooperate into tumorigenesis is its interaction with c-Myc, which is shown in a study on the mouse model of B cell lymphoma. In this study, it is demonstrated that one of the miR-17 to 92 components, miR-19, acts as an activator for the Akt-mTOR signaling pathway, therefore it suppresses the PTENgene to promote cell proliferation by C-Myc [65]. Also, there is evidence which supports the idea that miR-17 to 92 can affect angiogenesis as well as expression of some oncogenic transcription factors such as E2F [66].

Several other studies address the role of miR-17 to 92 in medulloblastoma tumorigenesis when cerebellar granule neuron progenitors (GNPs) fail to undergo cell differentiation, medulloblastoma occurs. The fact that one of the key components in the determination of cell differentiation is miRNA, therefore, the possible role of this noncoding RNA cannot be neglected in the progression of tumorigenesis of medulloblastoma [67].

One study shows that the expression of miR-17 to 92 in mouse 
helps with the development of the cerebellum and the proliferation of GNPs but not in postmitotic and differentiated neurons. Also, the miR-17 to 92 cluster has shown overexpression in medulloblastoma with activated SHH/PTCH signaling pathways which suggest that the miR-17 to 92 and SHH/PTCH pathways are functionally associated and contribute in the development of medulloblastoma in human and mouse models [68,69].

\section{2. microRNA-lethal-7 role as a tumor suppressor in medulloblastoma}

The lethal-7 (let-7) loci are on 9q22.32 and this miRNA was at first demonstrated in Caenorhabditis elegans which consists of a gene that encodes 9 miRNAs with the same seed sequence and acts as a control checkpoint of the cell cycle to exit and terminal differentiation. The let-7 can be found in Drosophila, which is one gene with a one miRNAs and the same seed sequence of $C$. elegans. In vertebrates, there are many more members of the let-7 family than C. elegans and Drosophila. Also, there are 9 members of the let-7 family that can be found in humans [70]. Many characteristics of let-7 are conserved across species, however, there are some noticeable differences that can be seen between them, such as, size which is smaller in invertebrates, the conservation of a pattern of let- 7 gene clustering and genomic positioning are conserved in flies and higher organisms, but it is not conserved in $C$. elegans. The major function of let- 7 can be addressed to promote the differentiation of cells. In C. elegans, let-7 inhibit the stem cell-like divisions of Seam cells. In higher organisms, let-7 is up-regulated during embryogenesis. It is shown that pri-let-7a and pri-let-7e and mature let-7a, let-7e, and let-7c are up-regulated during mouse brain development [71]. In addition, in breast-stem cell progenitors, let-7 up-regulated as the cells differentiated. Additionally, the reduced level of let-7 demonstrated in many types of cancer [72]. Recently it has been discovered that the let-7 family carries out the tumor suppressive function and it is shown that let-7 locus is deleted and down-regulated in different cancers, for instance, lung cancer, head, and neck squamous carcinoma, melanoma. On the other hand, overexpression of this miRNA led to cancer cell grows inhibition $[70,73,74]$. The let-7 can directly target oncogenes such as RAS, MYC, and HMGA2 by 3' UTR dependent manner [75,76].

\section{Down-regulation of miR-214 associated with tumor poor prognosis in medulloblastoma}

miRNA-214 is a member of the miR-214 family, has shown dysregulated expression associated with several cancers like breast cancer, hepatocellular carcinoma, lung cancer, esophageal squamous cell cancer, and ovarian cancer [77-80]. Researches showed dysregulation of miR-214 associated with poor prognosis in the aforementioned cancers. It is shown that down-regulation of miR-214 is the fundamental mechanism in which cell proliferation and cancers can occur, therefore several genes such as PTEN, LHX6, GALNT7, and EZH2 are identified as potential miR-214 target genes [77,81].

Though miR-214 functions as tumor-suppressors, other studies indicate its role in cancers such as medulloblastoma as an OncomiR. This shows the complexity and the different layers of gene regulation under the influence of microenvironment on different genes in different conditions in multicellular organisms [82].

\section{4. miR-9 act as a tumor suppressor in medulloblastoma}

miR-9 is located on 1q22 and also has 1 exon. It was initially discovered by neurobiologist that miR-9 is the most highly expressed miRNA during the development of the brain in all vertebrate. The miR-9 regulates the expression of several transcription factors including, FoxG1, Hes1, or Tlx. miR-9 was at first found in neurogenesis but it shows tumor suppressor activities in various cancers such as colorectal cancer, small cell lung cancer. In colorectal cancer, it is demonstrated that the restoration of miR-9, considerably inhibits colorectal cancer cell growth and metastasis [36,83], also miR-9 down-regulation in postmitotic neurons results in neurodegenerative diseases which implies the important role of miR-9 in neuronal development [84]. In medulloblastoma, miR-9 is suppressed via specific CpG island hypermethylation and it is one of the reasons for the poor prognosis of this cancer tumor [85]. In addition, Deletion of miR-9 can suppress the expression of cell cycle inhibitor p27 that results in cell proliferation and tumor initiation causing medulloblastoma [86].

\section{5. miR-326 down-regulation in medulloblastoma}

The miR-326 is located on the 11q13 on chromosomes. The miR-326 is shown to significantly suppress the cell growth by inhibition of cyclin D1, cyclin D2, CDK4 and up-regulation of p57 and p21. In addition, miR-326 activates apoptosis by up-regulation of key apoptosis genes and down-regulation of anti-apoptotic genes [87]. Moreover, miR-326 is discovered to have a role in the inhibition of cell migration and invasiveness through inhibition of matrix metalloproteins MMP7 and MMP9 in various organs. The miR-326 is known as a tumor suppressor and it is shown to down-regulated in various types of cancers, such as colorectal cancer, breast cancer, glioma, glioblastoma, and, brain tumors [88]. This miRNA is associated with Notch signaling pathway for 
brain development and glioma which is the aggressive form of a brain tumor. This miRNA was shown to suppress by NOTCH and it can suppress the NOTCH itself in a feedback loop. The miR-326 also interacts with the SHH signaling pathway by downregulating the SMO protein which results in cell proliferation inhibition [89]. The mir-326 suppresses the SHH signaling pathway and by that, it can control the development of cerebellar neuronal progenitors and tumor cells, indicating that mir-326 down-regulation has a role in medulloblastoma and other types of brain tumors [49].

\section{6. miR-199 family in medulloblastoma}

The miR-199a is a vertebrate-specific miRNA and there are two loci for the miR-199 family, one of them (miR-199a-1) is on the chromosome 19 and the other one (miR-199a-2) is located on the chromosome 1. Both of these loci encode the same miR-199a sequence. On chromosome 1, miR-199a is co-transcribed with miR-214 both of which contribute to the formation of the skeletal system [90]. The miR-199a is transcribed from the intron of the opposite strand of the Dynamin gene, GTPase family proteins that are responsible for the endocytosis in eukaryotic cells. It is shown that miR-199a and miR-199b control the expression of important mediators of endocytosis, such as clathrin heavy chain, Rab5A, Low-density lipoprotein receptor, and caveolin-1 [91,92].

The miR-199 family (miR-199a-3p/-5p and miR-199b-3p/-5p) were down-regulated in different cancers and are classified as a tumor-suppressor miRNAs [93]. In medulloblastoma, not only the different pathways genes cooperate into the progression of cells towards the cancerous state, but also the genes interplay conversation between pathways which adds more complexity to cancerous mechanisms [94]. Notch pathway effector, HES1 gene, shows overexpression in medulloblastoma stem cells and granule-cell progenitors in which loss of expression of miR-199-5p was demonstrated to be mostly within the metastatic state of cancer by hypermethylation and silencing of the miR-199-5p locus. Also, the Notch pathway seems to have a cross-talk with SHH and other pathways [50,95].

\section{7. miR-125 family down-regulated in medulloblastoma}

The miR-125 family consists of three members (miR-125a, miR-125b, and miR-125-2) which are highly conserved throughout various species [96]. miR-125a has been located at 19q13, however, miR-125b has been found to be located on two loci, 11q23 (hsa-miR-125b-1) and 21q21. The miR-125 family has been reported to be involved in a variety of carcinomas and other diseases. Members of this family have been connected to various cellular functions including, cell differentiation, proliferation, and apoptosis by targeting many different transcription factors, matrix-metalloprotease, growth factors. It was shown that miR-125 down-regulated in different cancers such as ovarian cancer, breast cancer, lung cancer, and brain tumors [97-99]. The function of the miR-125 family is to target and suppress matrix metalloprotease gene, BCL-2 gene, and so on [100]. The miR-125b suppresses the E2F2 proteins in CD133 positive cells and GScs in which they inhibit stem cell markers, but in glioblastoma, it is shown that the miR-125b is down-regulated [98]. Several studies have indicated that miR-125a can be activated by epidermal growth factor receptor which plays as a metastatic suppressor in lung cancer. MiR-125 up-regulation blocks the expression of MMP11 and vascular endothelial growth factor-A that leads to malignant phenotypes of many cancers [96]. Investigations have shown the roles of miR-125b in medulloblastoma and other brain tumors. Some studies indicate that miR-125a was down-regulated in medulloblastoma [48].

\section{Down-regulation of microRNA-124 in medulloblastoma}

MiR-124 is a highly conserved miRNA and its mature miRNA constructed from three precursor variants that are located on chromosomes 8q23.1 (miR-124-1), 8q12.3 (miR-124-2), and 20q13.33 (miR-124-3). MiR-124 has shown a different pattern of expression in various types of cancers. In some cancers, miR-125 displays down-regulation, including osteosarcoma, glioblastoma, and medulloblastoma [101-104]. It upregulates in several other cancers such as breast cancer. The down-regulated expression of miR-124 followed by brain tumor growths in medulloblastoma acts as a tumor suppressor [102]. Several studies indicate that overexpression of miR-124, which can inhibit the expression of CDK6 and prevent cell proliferation of medulloblastoma. Up-regulation of CDK6 has been seen in one-third of medulloblastomas. Several other studies indicated that miR-124 could also inhibit SLC16A1 in medulloblastoma. SLC16A1 acts on the efflux lactic acid during aerobic glycolysis. Down-regulation of miR-124 is common in medulloblastoma which can induce cell growth and proliferation [102].

\section{The microRNA-324 role as a tumor suppressor in medulloblastoma}

The miR-324-5p is located on 17p13.1 and it consists of 20-24 nucleotides. Both miR-324-5p and miR-324-3p are produced from a single pre-miRNA. The pre-miR-324 is composed of a $5 p$ arm and a $3 p$ arm with one terminal loop and soon after its transportation from the nucleus to the cytoplasm by exportin 5, it is further 
processed by the DICER so that its terminal loop is cut off from 5p-3p RNA duplex. Depending on which of these strands was loaded onto RISC, either the miR-324-5p or 3p is generated. The functions of micro RNAs varies a lot, but normally they contribute to the process of regulation which controls cell growth and proliferation. One of the roles of miR-324 is to contribute to neuronal differentiation alongside with miR-151 and miR-181 by suppressing cell proliferation.

The miR-324-3p and 5p are both generated from the same pre-miRNA but they have a variety of gene targets and gene expressions. In terms of their gene expression, miR-324 shows either up-regulation or down-regulation in various types of cancers. It is shown that miR-324 down-regulated in many types of cancers, such as hepatocellular carcinoma, glioblastoma, and medulloblastoma [105]. The miR-324-5p down-regulation is associated with metastasis and the invasion state in cancer [106]. In addition, in glioblastoma down-regulation of miR-324 is associated with poor prognostic and survival rate. The polycomb repressive complex 2 (PRC2) is one of the crucial elements in cancer initiation, progression, and invasion. The methyltransferase Enhancer of Zest Homolog 2 (EZH2) is an important part of the $\mathrm{PRC} 2$ protein, which is considered as an oncogene since it contributes to methylation of histone $\mathrm{H} 3$ lysine 27 of the tumor suppressor genes. The miR-324-5p suppresses EZH2 and functions as a tumor suppressor micro RNA in high-grade glioma tumor (glioblastoma) [86]. In medulloblastoma that is associated with SHH pathway, it is shown that the overexpression of Gli coincides with the down-regulation of some miRNAs, such as miR-324-5p which in fact can reinforce the tumor suppressor activities of miR-324-5p in cancers $[107,108]$.

\section{Down-regulation of miR-218 coincide with cancer invasiveness}

Like any other micro-RNAs, miR-218 is considered to be a short noncoding RNA that is transcribed by RNA polymerase II and is processed by Drosha and Dicer ribonuclease in order to become a mature micro-RNA. By incorporating the miR-218 into an RISC, it achieves the ability to exert its function through translational inhibition or destabilizing the target mRNA. The miR-218 gene is located on 4p15.31 and it is shown that miR-218 is vertebratespecific and it exists in a wide range of vertebrate species. It is shown that the expression of miR-218 is up-regulated directly by hexametric Isl1-Lhx3 complex which in turn determines the fate of the motor neurons and any aberration in miR-218 expression is followed by hyperexcitability, neuromuscular junction failure, and neurodegeneration [109].
The aberrant expression of miR-218 is also linked to many types of cancers, such as oral squamous carcinoma, Nasopharyngeal carcinoma, bladder cancer, breast cancer, and medulloblastoma $[110,111]$. Many studies provide evidence that the miR-218 is highly down-regulated in those cancers and this down-regulation is accompanied by cell migration, tumor invasiveness, and metastasis. The overexpression of miR-218 in different tumors shows a significant reduction in cell growth, colony formation, and invasiveness. All of these observations indicate that miR-218 acts as a tumor suppressor and its expression significantly decreases in cancerous tumors [112,113]. By using the overexpression of miR-218 and RNA-seq tools, researchers have identified 618 genes in which their transcriptions are suppressed by miR-218 and existing among those genes are, CDk6, RICTOR (RPTOR independent companion of MTOR, complex 2), CTSB (cathepsin B) [51].

\section{CONCLUSION AND PERSPECTIVE}

In this review, we identified 117 high-quality published studies that provided strong evidence that miRNAs can be suggested as promising key molecules in medulloblastoma formation and progression. The mechanisms by which miRNAs show their association with tumorigenesis provide the meaningful idea that miRNAs are a suitable subject for future medical treatment of medulloblastoma therapy. Today an unprecedented progression in technology and the several devised new techniques are promising to find solutions for miRNAs challenging researches with the focus on cancer therapy. Also, in these novel methods are; large-scale analyses of clinical studies, biological processes and systems, a meta-analysis of different data. These seem to lead to an answer in the near future. Although significant efforts remain and several questions must be answered, we predict that these innovative technologies will drastically change the medical practice in the foreseeable future.

\section{CONFLICTS OF INTEREST}

No potential conflicts of interest were disclosed.

\section{REFERENCES}

1. Bondy ML, Scheurer ME, Malmer B, Barnholtz-Sloan JS, Davis FG, Il'yasova D, et al. Brain tumor epidemiology: consensus from the Brain Tumor Epidemiology Consortium. Cancer 2008; 113:1953-68.

2. Prastawa M, Bullitt E, Ho S, Gerig G. A brain tumor segmenta- 
tion framework based on outlier detection. Med Image Anal 2004:8:275-83

3. Zülch K. Principles of the new World Health Organization (WHO) classification of brain tumors. Neuroradiology 1980;19:59-66.

4. DeAngelis LM. Brain tumors. N Engl J Med 2001;344:114-23.

5. Carrie C, Alapetite C, Mere P, Aimard L, Pons A, Kolodie H, et al. Quality control of radiotherapeutic treatment of medulloblastoma in a multicentric study: the contribution of radiotherapy technique to tumour relapse. The French Medulloblastoma Group. Radiother Oncol 1992;24:77-81.

6. Eberhart CG, Tihan T, Burger PC. Nuclear localization and mutation of beta-catenin in medulloblastomas. J Neuropathol Exp Neurol 2000;59:333-7.

7. McLaughlin MR, Gollin SM, Lese CM, Albright AL. Medulloblastoma and glioblastoma multiforme in a patient with Turcot syndrome: a case report. Surg Neurol 1998:49:295-301.

8. Itoh $\mathrm{H}$, Ohsato $\mathrm{K}$, Yao $\mathrm{T}$, Iida $\mathrm{M}$, Watanabe $\mathrm{H}$. Turcot's syndrome and its mode of inheritance. Gut 1979;20:414-9.

9. Hirsch JF, Renier D, Czernichow P, Benveniste L, Pierre-Kahn A. Medulloblastoma in childhood. Survival and functional results. Acta Neurochir (Wien) 1979:48:1-15

10. Rutkowski S, von Hoff $\mathrm{K}$, Emser A, Zwiener I, Pietsch T, Figarella-Branger D, et al. Survival and prognostic factors of early childhood medulloblastoma: an international meta-analysis. J Clin Oncol 2010:28:4961-8.

11. Northcott PA, Korshunov A, Witt H, Hielscher T, Eberhart CG, Mack S, et al. Medulloblastoma comprises four distinct molecular variants. J Clin Oncol 2011;29:1408-14.

12. Ellison DW, Dalton J, Kocak M, Nicholson SL, Fraga C, Neale G, et al. Medulloblastoma: clinicopathological correlates of SHH, WNT, and non-SHH/WNT molecular subgroups. Acta Neuropathol 2011:121:381-96.

13. Northcott PA, Shih DJ, Peacock J, Garzia L, Morrissy AS, Zichner $\mathrm{T}$, et al. Subgroup-specific structural variation across 1,000 medulloblastoma genomes. Nature 2012;488:49-56.

14. Taylor MD, Northcott PA, Korshunov A, Remke M, Cho YJ, Clifford SC, et al. Molecular subgroups of medulloblastoma: the current consensus. Acta Neuropathol 2012;123:465-72.

15. Shaabanpour Aghamaleki F, Mollashahi B, Aghamohammadi N, Rostami N, Mazloumi Z, Mirzaei H, et al. Bioinformatics analysis of key genes and pathways for medulloblastoma as a therapeutic target. Asian Pac J Cancer Prev 2018;20:221-7.

16. Lindsey JC, Lusher ME, Anderton JA, Bailey S, Gilbertson RJ, Pearson $\mathrm{AD}$, et al. Identification of tumour-specific epigenetic events in medulloblastoma development by hypermethylation profiling. Carcinogenesis 2004:25:661-8.

17. Murchison EP, Hannon GJ. miRNAs on the move: miRNA biogenesis and the RNAi machinery. Curr Opin Cell Biol 2004;6:223-9.

18. Farivar S, Shaabanpour Aghamaleki F. Effects of major epigenetic factors on systemic lupus erythematosus. Iran Biomed J 2018:22:294-302.

19. Bartel DP. MicroRNAs: genomics, biogenesis, mechanism, and function. Cell 2004;116:281-97.

20. Gregory RI, Shiekhattar R. MicroRNA biogenesis and cancer. Cancer Res 2005;65:3509-12.

21. Siomi H, Siomi MC. Posttranscriptional regulation of microRNA biogenesis in animals. Mol Cell 2010;38:323-32.

22. Cai Y, Yu X, Hu S, Yu J. A brief review on the mechanisms of miRNA regulation. Genomics Proteomics Bioinformatics 2009;7:
$147-54$.

23. Pereira DM, Rodrigues PM, Borralho PM, Rodrigues CM. Delivering the promise of miRNA cancer therapeutics. Drug Discov Today 2013;18:282-9.

24. Mitchell PS, Parkin RK, Kroh EM, Fritz BR, Wyman SK, Pogosova-Agadjanyan EL, et al. Circulating microRNAs as stable blood-based markers for cancer detection. Proc Natl Acad Sci U S A 2008;105:10513-8.

25. Gratas C, Tohma Y, Van Meir EG, Klein M, Tenan M, Ishii N, et al. Fas ligand expression in glioblastoma cell lines and primary astrocytic brain tumors. Brain Pathol 1997;7:863-9.

26. Skog J, Würdinger T, van Rijn S, Meijer DH, Gainche L, Sena-Esteves $\mathrm{M}$, et al. Glioblastoma microvesicles transport RNA and proteins that promote tumour growth and provide diagnostic biomarkers. Nat Cell Biol 2008;10:1470-6.

27. Feinberg AP. The epigenetics of cancer etiology. Semin Cancer Biol 2004; 14:427-32.

28. Muñoz N, Castellsagué X, de González AB, Gissmann L. HPV in the etiology of human cancer. Vaccine 2006:24 Suppl 3:S3/1-10.

29. Volinia S, Calin GA, Liu CG, Ambs S, Cimmino A, Petrocca F, et al. A microRNA expression signature of human solid tumors defines cancer gene targets. Proc Natl Acad Sci U S A 2006;103:2257-61.

30. Croce CM, Calin GA. miRNAs, cancer, and stem cell division. Cell 2005;122:6-7.

31. Di Leva G, Croce CM. miRNA profiling of cancer. Curr Opin Genet Dev 2013;23:3-11.

32. Esquela-Kerscher A, Slack FJ. Oncomirs - microRNAs with a role in cancer. Nat Rev Cancer 2006:6:259-69.

33. Zhang L, Huang J, Yang N, Greshock J, Megraw MS, Giannakakis A, et al. microRNAs exhibit high frequency genomic alterations in human cancer. Proc Natl Acad Sci U S A 2006;103:9136-41.

34. Brase JC, Wuttig D, Kuner R, Sültmann H. Serum microRNAs as non-invasive biomarkers for cancer. Mol Cancer 2010;9:306.

35. Tryndyak VP, Ross SA, Beland FA, Pogribny IP. Down-regulation of the microRNAs miR-34a, miR-127, and miR-200b in rat liver during hepatocarcinogenesis induced by a methyl-deficient diet. Mol Carcinog 2009;48:479-87.

36. Lehmann U, Hasemeier B, Christgen M, Müller M, Römermann $\mathrm{D}$, Länger $\mathrm{F}$, et al. Epigenetic inactivation of microRNA gene hsa-mir-9-1 in human breast cancer. J Pathol 2008;214:17-24.

37. Kano M, Seki N, Kikkawa N, Fujimura L, Hoshino I, Akutsu Y, et al. miR-145, miR-133a and miR-133b: tumor-suppressive miRNAs target FSCN1 in esophageal squamous cell carcinoma. Int J Cancer 2010;127:2804-14

38. Matsushita R, Yoshino H, Enokida H, Goto Y, Miyamoto K, Yonemori $\mathrm{M}$, et al. Regulation of UHRF1 by dual-strand tumor-suppressor microRNA-145 (miR-145-5p and miR-145-3p): inhibition of bladder cancer cell aggressiveness. Oncotarget 2016;7:28460-87.

39. Iorio MV, Croce CM. MicroRNAs in cancer: small molecules with a huge impact. J Clin Oncol 2009;27:5848-56.

40. Garzon R, Fabbri M, Cimmino A, Calin GA, Croce CM. MicroRNA expression and function in cancer. Trends Mol Med 2006; 12:580-7.

41. Cimmino A, Calin GA, Fabbri M, Iorio MV, Ferracin M, Shimizu $\mathrm{M}$, et al. miR-15 and miR-16 induce apoptosis by targeting BCL2. Proc Natl Acad Sci U S A 2005;102:13944-9.

42. Akao Y, Nakagawa Y, Hirata I, Iio A, Itoh T, Kojima K, et al. Role of anti-oncomirs miR-143 and -145 in human colorectal tumors. 
Cancer Gene Ther 2010:17:398-408.

43. Eis PS, Tam W, Sun L, Chadburn A, Li Z, Gomez MF, et al. Accumulation of miR-155 and BIC RNA in human B cell lymphomas. Proc Natl Acad Sci U S A 2005;102:3627-32.

44. Yanaihara N, Caplen N, Bowman E, Seike M, Kumamoto K, Yi M, et al. Unique microRNA molecular profiles in lung cancer diagnosis and prognosis. Cancer Cell 2006;9:189-98.

45. Slaby O, Svoboda M, Fabian P, Smerdova T, Knoflickova D, Bednarikova $M$, et al. Altered expression of miR-21, miR-31, miR-143 and miR-145 is related to clinicopathologic features of colorectal cancer. Oncology 2007:72:397-402.

46. Chen X, Guo X, Zhang H, Xiang Y, Chen J, Yin Y, et al. Role of miR-143 targeting KRAS in colorectal tumorigenesis. Oncogene 2009;28:1385-92.

47. Olive V, Jiang I, He L. mir-17-92, a cluster of miRNAs in the midst of the cancer network. Int J Biochem Cell Biol 2010;42:1348-54.

48. Ferretti E, De Smaele E, Po A, Di Marcotullio L, Tosi E, Espinola MS, et al. MicroRNA profiling in human medulloblastoma. Int J Cancer 2009; 124:568-77.

49. Jiang Z, Cushing L, Ai X, Lü J. miR-326 is downstream of Sonic hedgehog signaling and regulates the expression of Gli2 and smoothened. Am J Respir Cell Mol Biol 2014:51:273-83.

50. Garzia L, Andolfo I, Cusanelli E, Marino N, Petrosino G, De Martino D, et al. MicroRNA-199b-5p impairs cancer stem cells through negative regulation of HES1 in medulloblastoma. PLOS One 2009;4:e4998.

51. Venkataraman S, Birks DK, Balakrishnan I, Alimova I, Harris PS, Patel PR, et al. MicroRNA 218 acts as a tumor suppressor by targeting multiple cancer phenotype-associated genes in medulloblastoma. J Biol Chem 2013;288:1918-28.

52. Nakajima G, Hayashi K, Xi Y, Kudo K, Uchida K, Takasaki K, et al. Non-coding microRNAs hsa-let-7g and hsa-miR-181b are associated with chemoresponse to S-1 in colon cancer. Cancer Genomics Proteomics 2006;3:317-24.

53. Gokhale A, Kunder R, Goel A, Sarin R, Moiyadi A, Shenoy A, et al. Distinctive microRNA signature of medulloblastomas associated with the WNT signaling pathway. J Cancer Res Ther 2010;6:521-9.

54. Cho WC. MicroRNAs: potential biomarkers for cancer diagnosis, prognosis and targets for therapy. Int J Biochem Cell Biol 2010; 42:1273-81

55. Pierson J, Hostager B, Fan R, Vibhakar R. Regulation of cyclin dependent kinase 6 by microRNA 124 in medulloblastoma. J Neurooncol 2008;90:1-7.

56. Salm F, Dimitrova V, von Bueren AO, Ćwiek P, Rehrauer H, Djonov V, et al. The phosphoinositide 3-kinase p110 $\alpha$ isoform regulates leukemia inhibitory factor receptor expression via c-Myc and miR-125b to promote cell proliferation in medulloblastoma. PLoS One 2015;10:e0123958.

57. Lv SQ, Kim YH, Giulio F, Shalaby T, Nobusawa S, Yang H, et al. Genetic alterations in microRNAs in medulloblastomas. Brain Pathol 2012;22:230-9.

58. Hayashita Y, Osada H, Tatematsu Y, Yamada H, Yanagisawa K, Tomida S, et al. A polycistronic microRNA cluster, miR-17-92, is overexpressed in human lung cancers and enhances cell proliferation. Cancer Res 2005;65:9628-32.

59. Ventura A, Young AG, Winslow MM, Lintault L, Meissner A, Erkeland SJ, et al. Targeted deletion reveals essential and overlapping functions of the miR-17 through 92 family of miRNA clusters. Cell 2008;132:875-86

60. Concepcion CP, Bonetti C, Ventura A. The microRNA-17-92 family of microRNA clusters in development and disease. Cancer J 2012;18:262-7.

61. Mendell JT. miRiad roles for the miR-17-92 cluster in development and disease. Cell 2008;133:217-22.

62. Takakura S, Mitsutake N, Nakashima M, Namba H, Saenko VA, Rogounovitch TI, et al. Oncogenic role of miR-17-92 cluster in anaplastic thyroid cancer cells. Cancer Sci 2008;99:1147-54.

63. Tanzer A, Stadler PF. Molecular evolution of a microRNA cluster. J Mol Biol 2004:339:327-35.

64. Matsubara H, Takeuchi T, Nishikawa E, Yanagisawa K, Hayashita Y, Ebi H, et al. Apoptosis induction by antisense oligonucleotides against miR-17-5p and miR-20a in lung cancers overexpressing miR-17-92. Oncogene 2007;26:6099-105.

65. Olive V, Bennett MJ, Walker JC, Ma C, Jiang I, Cordon-Cardo C, et al. miR-19 is a key oncogenic component of mir-17-92. Genes Dev 2009:23:2839-49.

66. Dews M, Fox JL, Hultine S, Sundaram P, Wang W, Liu YY, et al. The myc-miR-17 92 axis blunts TGF $\{$ beta $\}$ signaling and production of multiple TGF $\{$ beta $\}$-dependent antiangiogenic factors. Cancer Res 2010;70:8233-46.

67. Uziel T, Karginov FV, Xie S, Parker JS, Wang YD, Gajjar A, et al. The miR-17 92 cluster collaborates with the Sonic Hedgehog pathway in medulloblastoma. Proc Natl Acad Sci U S A 2009; 106:2812-7.

68. Murphy BL, Obad S, Bihannic L, Ayrault O, Zindy F, Kauppinen S, et al. Silencing of the miR-17 $\sim 92$ cluster family inhibits medulloblastoma progression. Cancer Res 2013;73;7068-78.

69. Northcott PA, Fernandez-L A, Hagan JP, Ellison DW, Grajkowska W, Gillespie Y, et al. The miR-17/92 polycistron is up-regulated in sonic hedgehog-driven medulloblastomas and induced by $\mathrm{N}$-myc in sonic hedgehog-treated cerebellar neural precursors. Cancer Res 2009;69:3249-55.

70. Reinhart BJ, Slack FJ, Basson M, Pasquinelli AE, Bettinger JC, Rougvie AE, et al. The 21-nucleotide let-7 RNA regulates developmental timing in Caenorhabditis elegans. Nature 2000;403: 901-6.

71. Rybak A, Fuchs H, Smirnova L, Brandt C, Pohl EE, Nitsch R, et al. A feedback loop comprising lin-28 and let-7 controls pre-let-7 maturation during neural stem-cell commitment. Nat Cell Biol 2008; 10:987-93.

72. Spizzo R, Nicoloso MS, Croce CM, Calin GA. SnapShot: MicroRNAs in cancer. Cell 2009;137:586. e1.

73. Büssing I, Slack FJ, Grosshans H. let-7 microRNAs in development, stem cells and cancer. Trends Mol Med 2008;14:400-9.

74. Yu F, Yao H, Zhu P, Zhang X, Pan Q, Gong C, et al. let-7 regulates self renewal and tumorigenicity of breast cancer cells. Cell 2007;131:1109-23.

75. Johnson SM, Grosshans H, Shingara J, Byrom M, Jarvis R, Cheng A, et al. RAS is regulated by the let-7 microRNA family. Cell 2005; 120:635-47.

76. Lee YS, Dutta A. The tumor suppressor microRNA let-7 represses the HMGA2 oncogene. Genes Dev 2007;21:1025-30.

77. Xia H, Ooi LL, Hui KM. MiR-214 targets $\beta$-catenin pathway to suppress invasion, stem-like traits and recurrence of human hepatocellular carcinoma. PLoS One 2012; 7:e44206.

78. Yang H, Kong W, He L, Zhao JJ, O'Donnell JD, Wang J, et al. MicroRNA expression profiling in human ovarian cancer: 
miR-214 induces cell survival and cisplatin resistance by targeting PTEN. Cancer Res 2008;68:425-33.

79. Zhang XJ, Ye H, Zeng CW, He B, Zhang H, Chen YQ. Dysregulation of miR-15a and miR-214 in human pancreatic cancer. J Hematol Oncol 2010;3:46.

80. Zhou Y, Hong L. Prediction value of miR-483 and miR-214 in prognosis and multidrug resistance of esophageal squamous cell carcinoma. Genet Test Mol Biomarkers 2013;17:470-4.

81. Schwarzenbach H, Milde-Langosch K, Steinbach B, Müller V, Pantel K. Diagnostic potential of PTEN-targeting miR-214 in the blood of breast cancer patients. Breast Cancer Res Treat 2012;134:933-41.

82. Sharma T, Hamilton R, Mandal CC. miR-214: a potential biomarker and therapeutic for different cancers. Future Oncol 2015:11:349-63.

83. Bandrés E, Cubedo E, Agirre X, Malumbres R, Zárate R, Ramirez $\mathrm{N}$, et al. Identification by Real-time PCR of 13 mature microRNAs differentially expressed in colorectal cancer and non-tumoral tissues. Mol Cancer 2006;5:29.

84. Hébert SS, De Strooper B. Alterations of the microRNA network cause neurodegenerative disease. Trends Neurosci 2009;32: 199-206.

85. Fiaschetti G, Abela L, Nonoguchi N, Dubuc AM, Remke M, Boro A, et al. Epigenetic silencing of miRNA-9 is associated with HES1 oncogenic activity and poor prognosis of medulloblastoma. Br J Cancer 2013;110:636-47.

86. Zhi T, Yu T, Pan M, Nie E, Wu W, Wang X, et al. EZH2 alteration driven by microRNA-524-5p and microRNA-324-5p promotes cell proliferation and temozolomide resistance in glioma. Oncotarget 2017:8:96239-48.

87. Kefas B, Comeau L, Floyd DH, Seleverstov O, Godlewski J, Schmittgen $T$, et al. The neuronal microRNA miR-326 acts in a feedback loop with notch and has therapeutic potential against brain tumors. J Neurosci 2009:29:15161-8.

88. Reddy KB. MicroRNA (miRNA) in cancer. Cancer Cell Int 2015;15:38.

89. Wang S, Lu S, Geng S, Ma S, Liang Z, Jiao B. Expression and clinical significance of microRNA-326 in human glioma miR-326 expression in glioma. Med Oncol 2013;30:373.

90. Murakami Y, Toyoda H, Tanaka M, Kuroda M, Harada Y, Matsuda F, et al. The progression of liver fibrosis is related with overexpression of the miR-199 and 200 families. PLoS One 2011;6:e16081.

91. Lee DY, Shatseva T, Jeyapalan Z, Du WW, Deng Z, Yang BB. A 3'-untranslated region (3'UTR) induces organ adhesion by regulating miR-199a* functions. PLoS One 2009;4:e4527.

92. Aranda JF, Canfrán-Duque A, Goedeke L, Suárez Y, FernándezHernando C. The miR-199-dynamin regulatory axis controls receptor-mediated endocytosis. J Cell Sci 2015;128:3197-209.

93. Koshizuka K, Hanazawa T, Kikkawa N, Arai T, Okato A, Kurozumi A, et al. Regulation of ITGA3 by the anti-tumor miR-199 family inhibits cancer cell migration and invasion in head and neck cancer. Cancer Sci 2017;108:1681-92.

94. Shen L, Sun C, Li Y, Li X, Sun T, Liu C, et al. MicroRNA-199a-3p suppresses glioma cell proliferation by regulating the AKT/mTOR signaling pathway. Tumour Biol 2015;36:6929-38.

95. Wang Z, Li Y, Kong D, Ahmad A, Banerjee S, Sarkar FH. Cross-talk between miRNA and Notch signaling pathways in tumor development and progression. Cancer Lett 2010;292:141-8.

96. Sun YM, Lin KY, Chen YQ. Diverse functions of miR-125 family in different cell contexts. J Hematol Oncol 2013;6:6.

97. Wang G, Mao W, Zheng S, Ye J. Epidermal growth factor receptor-regulated miR-125a-5p: a metastatic inhibitor of lung cancer. FEBS J 2009;276:5571-8.

98. Wu N, Xiao L, Zhao X, Zhao J, Wang J, Wang F, et al. miR-125b regulates the proliferation of glioblastoma stem cells by targeting E2F2. FEBS Lett 2012;586:3831-9.

99. Zhou M, Liu Z, Zhao Y, Ding Y, Liu H, Xi Y, et al. MicroRNA-125b confers the resistance of breast cancer cells to paclitaxel through suppression of pro-apoptotic Bcl-2 antagonist killer 1 (Bak1) expression. J Biol Chem 2010;285:21496-507.

100. Yin H, Sun Y, Wang X, Park J, Zhang Y, Li M, et al. Progress on the relationship between miR-125 family and tumorigenesis. Exp Cell Res 2015:339:252-60.

101. Hunt S, Jones AV, Hinsley EE, Whawell SA, Lambert DW. MicroRNA-124 suppresses oral squamous cell carcinoma motility by targeting ITGB1. FEBS Lett 2011:585:187-92.

102. Li KK, Pang JC, Ching AK, Wong CK, Kong X, Wang Y, et al. miR-124 is frequently down-regulated in medulloblastoma and is a negative regulator of SLC16A1. Hum Pathol 2009;40: $1234-43$.

103. Wang MJ, Li Y, Wang R, Wang C, Yu YY, Yang L, et al. Downregulation of microRNA-124 is an independent prognostic factor in patients with colorectal cancer. Int J Colorectal Dis 2013:28:183-9.

104. Zheng F, Liao YJ, Cai MY, Liu YH, Liu TH, Chen SP, et al. The putative tumour suppressor microRNA-124 modulates hepatocellular carcinoma cell aggressiveness by repressing ROCK2 and EZH2. Gut 2012;61:278-89.

105. Kuo WT, Yu SY, Li SC, Lam HC, Chang HT, Chen WS, et al. MicroRNA-324 in human cancer: miR-324-5p and miR-324-3p have distinct biological functions in human cancer. Anticancer Res 2016;36:5189-96.

106. Zhang HQ, Sun Y, Li JQ, Huang LM, Tan SS, Yang FY, et al. The expression of microRNA-324-3p as a tumor suppressor in nasopharyngeal carcinoma and its clinical significance. Onco Targets Ther 2017;10:4935-43.

107. Katoh Y, Katoh M. Hedgehog target genes: mechanisms of carcinogenesis induced by aberrant hedgehog signaling activation. Curr Mol Med 2009:9:873-86.

108. Tang B, Xu A, Xu J, Huang H, Chen L, Su Y, et al. MicroRNA324-5p regulates stemness, pathogenesis and sensitivity to bortezomib in multiple myeloma cells by targeting hedgehog signaling. Int J Cancer 2018;142:109-20.

109. Thiebes KP, Nam H, Cambronne XA, Shen R, Glasgow SM, Cho $\mathrm{HH}$, et al. miR-218 is essential to establish motor neuron fate as a downstream effector of Isl1-Lhx3. Nat Commun 2015;6:7718.

110. Alajez NM, Lenarduzzi M, Ito E, Hui AB, Shi W, Bruce J, et al. MiR-218 suppresses nasopharyngeal cancer progression through downregulation of survivin and the SLIT2-ROBO1 pathway. Cancer Res 2011;71:2381-91.

111. Uesugi A, Kozaki K, Tsuruta T, Furuta M, Morita K, Imoto I, et al. The tumor suppressive microRNA miR-218 targets the mTOR component Rictor and inhibits AKT phosphorylation in oral cancer. Cancer Res 2011;71:5765-78.

112. Song L, Huang Q, Chen K, Liu L, Lin C, Dai T, et al. miR-218 inhibits the invasive ability of glioma cells by direct downregulation of IKK- $\beta$. Biochem Biophys Res Commun 2010;402: $135-40$. 
113. Liu W, Gong YH, Chao TF, Peng XZ, Yuan JG, Ma ZY, et al. Identification of differentially expressed microRNAs by micro- array: a possible role for microRNAs gene in medulloblastomas. Chin Med J (Engl) 2009;122:2405-11. 